\title{
As narrativas de estudantes de enfermagem nos portfólios do Estágio Curricular Supervisionado*
}

The narrative of nursing students in their Supervised Curricular Internship portfolios

Testimonios de estudiantes de enfermería en portfolios de Pasantía Curricular Supervisada

Nádia Frazão Rossi ${ }^{1}$, Cinira Magali Fortuna ${ }^{2}$, Silvia Matumoto ${ }^{3}$, Franciele Maia Marciano ${ }^{4}$, Jael Bernardes da Silva ${ }^{5}$, Juliana Sterci da Silva ${ }^{6}$

\footnotetext{
* Artigo fruto de pesquisa financiada através de bolsa de estudos pelo "Projeto Ensinar com Pesquisa da Universidade de São Paulo".

1 Enfermeira. Ribeirão Preto, SP, Brasil. E-mail: nadia.ross@usp.br.

2 Enfermeira, Doutora em Enfermagem em Saúde Pública. Professora Doutora da Escola de Enfermagem de Ribeirão Preto da Universidade de São Paulo (EERP/USP). Ribeirão Preto, SP, Brasil. E-mail: fortuna@eerp.usp.br.

${ }^{3}$ Enfermeira, Doutora em Enfermagem em Saúde Pública. Professora Doutora da EERP/USP. Ribeirão Preto, SP, Brasil. E-mail: smatumoto@eerp.usp.br.

${ }^{4}$ Enfermeira, Mestre em Enfermagem em Saúde Pública. Enfermeira da Secretaria Municipal de Saúde de Cumari. Cumari, GO, Brasil. E-mail:

francielemarciano@usp.br.

${ }^{5}$ Enfermeira, Mestre em Enfermagem em Saúde Pública. Discente do Programa de Pós-Graduação em Enfermagem em Saúde Pública, nível Doutorado, da EERP/USP. Ribeirão Preto, SP, Brasil. E-mail: jaelbs@yahoo.com.br.

${ }^{6}$ Enfermeira. Discente do Programa de Pós-Graduação em Enfermagem em Saúde Pública, nível Mestrado, da EERP/USP. Ribeirão Preto, SP, Brasil. E-mail: julianasterci@usp.br.
}

\section{RESUMO}

A formação crítico-reflexiva do enfermeiro é um desafio. Um dos instrumentos utilizados para desenvolver esta capacidade é o portfólio reflexivo. Este estudo qualitativo objetivou identificar os tipos de narrativas que estão presentes nos portfólios e analisar as reflexões dos estudantes na disciplina Estágio Curricular Supervisionado. Onze portfólios foram analisados, identificando-se a presença de narração descritiva, reflexão descritiva, reflexão dialógica e crítica, com posterior análise temática. Foram identificados os quatro tipos de narrativas. O foco das reflexões conformou três categorias temáticas: análise sobre o campo de estágio; apropriação e análise do trabalho do enfermeiro; e aprendizagens durante o Estágio Curricular Supervisionado. Conclui-se que aspectos relevantes na vivência do Estágio Curricular Supervisionado têm sido apreendidos e sistematizados nos portfólios, embora seja desejável o avanço na reflexão crítica. A análise do tipo de narrativas dos estudantes pode contribuir para a orientação do processo de avaliação formativa de enfermeiros, na perspectiva críticoreflexiva.

Descritores: Competência Profissional; Conhecimentos, Atitudes e Prática em Saúde; Educação em Enfermagem.

\section{ABSTRACT}

The critical-reflective training of nurses is a challenge. The reflective portfolio is an instrument used for developing this capacity. The aim of this qualitative study was to identify the types of narratives present in such portfolios and analyze the reflections of students enrolled in the Supervised Curricular Internship. Eleven portfolios were analyzed, and the narratives found were descriptive, reflective and descriptive, reflective and dialogic, and critical with subsequent thematic analysis. We identified four types of narratives. Reflections were focused around three thematic categories: an analysis of the internship's field of work; assimilation and analysis of the nursing professional's work; and what was learned throughout the Supervised Curricular Internship. The relevant aspects of the internship experience were apprehended and systematized through the portfolios, although more in-depth critical reflection is needed. The analysis of narrative types presented by students can contribute to guiding the process of nursing training evaluation towards critical reflection.

Descriptors: Professional Competence; Health Knowledge, Attitudes, Practice; Education, Nursing.

\section{RESUMEN}

La formación crítico-reflexiva del enfermero constituye un desafío. Un instrumento utilizado para desarrollar esta capacidad es el portfolio reflexivo. Estudio cualitativo que objetivó identificar los tipos de testimonios presentes en los portfolios y analizar las reflexiones de estudiantes de la materia Pasantía Curricular Supervisada. Fueron analizados once portfolios, identificándose presencia de narración descriptiva, reflexión descriptiva, reflexión dialógica y critica con posterior análisis temático. Fueron identificados los cuatro tipos de narración. El foco de las reflexiones conformó tres categorías temáticas: análisis del local de pasantía, apropiación y análisis del trabajo del enfermero; y aprendizajes durante la Pasantía Curricular Supervisada. Se concluye en que fueron aprendidos aspectos relevantes durante la Pasantía Curricular Supervisada, aunque sería deseable un avance en la reflexión crítica. El análisis del tipo de testimonios de estudiantes puede ayudar a orientar el proceso de evaluación formativa de enfermeros en la perspectiva crítico-reflexiva.

Descriptores: Competencia Profesional; Conocimientos, Actitudes y Práctica en Salud; Educación en Enfermería. 


\section{INTRODUÇÃO}

A formação de profissionais de saúde no Brasil, dentre eles o enfermeiro, tem sido estruturada na especialização precoce e no preparo centrado no uso de tecnologias que nem sempre respondem às necessidades de saúde da população(1). Além disso, as rápidas transformações do conhecimento e dos valores, bem como as do trabalho solicitam a formação de um profissional crítico-reflexivo capaz de responder a tais demandas $^{(1-2)}$. Isto é, que seja capaz de analisar a realidade vivenciada, questioná-la, compreendê-la em múltiplos ângulos e propor alternativas de modo democrático ${ }^{(2)}$.

Essas competências estão oficializadas nas Diretrizes Curriculares Nacionais para os Cursos de Graduação em Enfermagem $^{(3)}$ que propõem a formação de um profissional crítico-reflexivo. Elas indicam que a articulação entre a formação profissional e o mundo do trabalho deve ser realizada desde o início do curso, focando a ação do enfermeiro generalista. Uma das expressões dessa articulação ensino-serviço é o Estágio Curricular Supervisionado (ECS) que a partir desta diretriz passou a ter caráter obrigatório(3).

O ECS consiste no contato direto do estudante com a realidade dos serviços de saúde, com a prática profissional dos trabalhadores do cenário de aprendizagem e com as necessidades de saúde da população, o que possibilita o desenvolvimento pessoal e profissional dos estudantes e dos demais profissionais envolvidos $^{(4)}$.

Nessa dinâmica de aprendizagem e formação profissional, espera-se que o estudante de enfermagem consiga sistematizar uma análise do serviço e implementar ações que contribuam com a qualificação e o exercício da assistência à saúde com ênfase no cuidado integral. Para isso, torna-se fundamental que ele reconheça e identifique criticamente a forma de organização do serviço por meio das atuações do enfermeiro, da caracterização do serviço, do perfil da clientela assistida, dos recursos oferecidos e da organização do processo de trabalho.

Assim, a capacidade reflexiva torna-se uma condição fundamental para a apropriação e síntese do trabalho do enfermeiro numa dimensão que ultrapassa o fazer técnico. Dentre as estratégias para o desenvolvimento dessa capacidade, destaca-se o portfólio reflexivo ${ }^{(5)}$. Ele é um instrumento de trabalho para o acompanhamento do processo de aprendizagem de estudantes, por ele mesmo e pela equipe pedagógica, compreendendo um conjunto de narrativas organizadas, comentadas e contextualizadas ${ }^{(5-6)}$.

O portfólio objetiva organizar os registros que se propõem a descrever, analisar e refletir a vivência à luz de referenciais teóricos, expressando a singularidade, os afetos, as dúvidas, entre outros aspectos, e promovendo o desenvolvimento de reflexões e o olhar crítico do profissional em formação ${ }^{(7)}$. Alguns autores ${ }^{(5-6,8)}$ reforçam a visão de que o portfólio é uma ferramenta que amplia os métodos de desenvolvimento e avaliação do estudante.

As narrativas das vivências registradas no portfólio potencializam a aprendizagem crítico-reflexiva, compromissada com a realidade, à medida que o aluno articula a prática profissional com os referenciais teóricos ${ }^{(9)}$. Sendo assim, no portfólio referente ao último estágio do curso, é possível analisar os tipos de narrativas presentes, buscando compreender o processo de reflexão e o percurso de aprendizagem do estudante com vistas a auxiliá-lo em seu processo formativo.

Elegeu-se, então, como objetivos deste estudo identificar os tipos de narrativas que estão presentes nos portfólios e analisar as reflexões produzidas pelos estudantes de enfermagem na disciplina Estágio Curricular Supervisionado.

A contribuição deste estudo está em indicar pistas sobre o processo formativo do enfermeiro críticoreflexivo por meio da análise das narrativas dos portfólios de estudantes de enfermagem. Tal análise pode servir como um balizador para a utilização dessa ferramenta no processo formativo.

Destaca-se que os estudos sobre portfólios na formação do enfermeiro são ainda escassos no Brasil e não se encontraram na literatura trabalhos que articulassem os tipos de narrativas dos portfólios e o Estágio Curricular Supervisionado.

\section{MÉTODO}

Trata-se de um estudo de abordagem qualitativa(10) que leva em consideração objetos singulares que estão em produção nas relações sociais.

A população do estudo foi composta por 11 portfólios de estudantes concluintes da disciplina Estágio Curricular Supervisionado de um curso de bacharelado e licenciatura em enfermagem de uma universidade pública, no primeiro semestre de 2011. Dos 22 estudantes, 11 concordaram em ceder seus portfólios para a análise documental, sendo este o critério de inclusão.

Os portfólios eram compostos de narrativas sobre as vivências no estágio na área de atenção básica e 
hospitalar, com número de páginas variando entre cinco e 32, totalizando 141 páginas de material empírico.

Todos os portfólios foram lidos na íntegra, e o primeiro passo da análise foi classificar o material quanto a sua natureza, identificando em qual modalidade os trechos se enquadravam: narração descritiva, reflexão descritiva, reflexão dialógica e reflexão crítica, tal classificação foi baseada no trabalho de Marcolino e Mizukami ${ }^{(11)}$.

A narração descritiva é uma observação subjetiva com levantamento de hipóteses, mas sem aprofundamento ou exploração das mesmas. Há o registro do fato sem justificativas.

$\mathrm{Na}$ descrição reflexiva, apresentam-se justificativas que podem ser baseadas tanto na literatura como no próprio julgamento. Há um esforço que denota inquietações.

Quanto à reflexão dialógica, trata-se de um diálogo consigo mesmo, uma busca de diferentes formas para explicar um fenômeno. Assim como a descrição reflexiva, a reflexão dialógica pode se basear na literatura ou no próprio julgamento.

Por fim, a reflexão crítica apresenta eventos por meio de múltiplos pontos de vista, considerando o contexto sócio-histórico-cultural e político.

Após a caracterização das reflexões, utilizou-se a análise de conteúdo temática ${ }^{(12)}$ para análise do conteúdo das reflexões dos estudantes durante o ECS, o que possibilitou o encontro de algumas categorias apresentadas a seguir. Os achados foram confrontados com dados já existentes na literatura e com o referencial teórico da produção de narrativas reflexivas como recurso pedagógico ${ }^{(11,13-16)}$ e da formação críticoreflexiva $^{(2)}$.

O projeto foi aprovado pelo Comitê de Ética em Pesquisa, protocolo no $1371 / 2011$. Todos os estudantes assinaram o Termo de Consentimento Livre e Esclarecido. Buscou-se garantir o anonimato dos participantes por meio da identificação dos fragmentos com a sigla $E$, seguida do número correspondente que foi atribuído a cada portfólio (ex: E1, E2), e o tipo de narrativa exemplificada.

\section{RESULTADOS}

Com relação ao tipo de narrativa, identificou-se a presença das quatro modalidades, sendo predominante a narração descritiva, seguida de reflexões descritivas e dialógicas. Houve a ocorrência de apenas um fragmento de reflexão crítica. Optou-se por exemplificar cada tipo de narrativa junto com as categorias temáticas.
Foram construídas três categorias temáticas, a partir das reflexões dos estudantes: Análise sobre o campo de estágio; Apropriação e análise do trabalho do enfermeiro e Aprendizagens durante o Estágio Curricular Supervisionado.

\section{Análise sobre o campo de estágio}

Os estudantes apresentam reflexões que contextualizam dificuldades e indicam desafios a serem enfrentados nos serviços de saúde, como exemplifica o fragmento:

Apesar da enorme importância dada à Atenção Básica pelas autoridades em saúde do país, importância esta reforçada pelas várias discussões do tema e ainda pelas publicações na área, cabe ressaltar que a realidade é muito dura com este modelo. A meu ver, parece que cada vez mais a Atenção Básica vem sendo desvalorizada aos olhos dos usuários da saúde, pelo seu sucateamento e falta de organização, o que enaltece as ações estritamente curativas da saúde, com valorização do modelo hospitalocêntrico e ações cada vez mais pontuais sem preocupação com a promoção da saúde e prevenção dos agravos (E10 Reflexão crítica).

O fragmento pode ser classificado como uma reflexão crítica, pois o estudante é capaz de articular a vivência, contextualizando sua observação através de múltiplas possibilidades de análise.

Em todos os portfólios, foi possível verificar a presença de referenciais teóricos para fundamentar as argumentações das experiências vivenciadas, como mostra o exemplo:

E como ressalta (Nome de autores) (2002) quanto maior o número de necessidades afetadas do cliente, maior é a necessidade de se planejar a assistência, uma vez que a sistematização das ações visa à organização, à eficiência e à validade da assistência prestada a fim de um cuidado humanizado e holístico. Será que precisamos ter na prescrição médica dos cuidados mudança de decúbito de 2/2horas? Esse já não é um cuidado de enfermagem? (E11 Descrição reflexiva).

Houve a explicitação de preocupações com relação à estrutura física inadequada:

Nessa enfermaria há uma porta de acesso ao expurgo da unidade, o que é questionável, uma vez que não é aconselhável manter o expurgo em uma área tão próxima aos pacientes internados. Outro motivo para 
reflexão o fato de o expurgo ser destinado a armazenar também materiais limpos (termômetros, bombas de infusão, almotolias de soluções antissépticas) levando a um cruzamento de materiais limpos com materiais contaminados (E2 Descrição reflexiva).

Outro tema frequente nas reflexões dos estudantes foi referente às relações estabelecidas pela equipe de saúde:

Esses trabalhadores, para lutarem contra o sofrimento advindo da tarefa primária, o cuidar, desenvolvem estratégias individuais e/ou coletivas de defesa. Elas supõem que muitos deles, para enfrentarem 0 sofrimento no trabalho, possam desenvolver sintomas psicoemocionais (somatização) para tentar preservar o equilíbrio psíquico. Isso olhando brevemente para saúde do trabalhador. Mas e o paciente, como será que fica o seu direito à assistência de sua saúde garantida por lei, já que temos teoricamente trabalhadores que pelo próprio processo de trabalho estão desgastados? O que a educação permanente tem a ver com a formação desses profissionais? (E11 Reflexão dialógica).

\section{Apropriação e análise do trabalho do enfermeiro}

Nesse tema foram agrupadas reflexões sobre o trabalho do enfermeiro, uma inquietação importante para o estudante nesse momento da formação.

A Sistematização de Enfermagem do [andar do hospital] não ocorre de forma efetiva. (...) os impressos não são utilizados de forma adequada. A admissão do paciente é sempre realizada, utilizando-se o impresso que auxilia na coleta de dados, porém dificilmente realiza-se o exame físico que deveria sempre ser preenchido junto com o da admissão. (...) a rotatividade dos pacientes é intensa, o que muitas vezes inviabiliza o preenchimento deste instrumento pela enfermeira, que deixa de coletar importantes dados não conseguindo realizar a consulta de enfermagem e exame físico que são extremamente importantes no planejamento da assistência integral do cliente (E6 Narração descritiva).

Houve reflexões sobre a forma de lidar dos enfermeiros com os conflitos e dilemas do cotidiano do trabalho.

Apesar de muitos problemas terem suas causas conhecidas, percebo que ninguém quer trabalhar com as causas e parecem tentar escondê-las com desculpas, às vezes parei para pensar sobre o motivo do receio que as enfermeiras e o gerente têm para não conversar com a equipe de trabalho sobre os problemas da Unidade, por que não se trabalhar com a corresponsabilização das questões, por que não discutir as situações, expor os problemas e tentar juntos encontrar soluções. (...). Volto a ressaltar, acho que isso pode ser atribuído à falta de liderança e comprometimento (E10 Reflexão descritiva).

O enfermeiro é percebido como agente importante na organização da equipe e do cuidado, e suas dificuldades foram objeto de reflexão em muitos dos portfólios.

Penso que o relacionamento interpessoal é a parte mais difícil do trabalho do enfermeiro, pois ele precisa aprender a lidar com os mais diversos tipos de pessoas, seja o paciente, a família do paciente, (...), a equipe de enfermagem e os seus superiores (E3 Reflexão dialógica).

\section{Aprendizagens no Estágio Curricular Supervisionado}

Essa categoria comporta as reflexões dos estudantes com relação à dinâmica da disciplina e do estágio para sua aprendizagem, tendo como uma das pautas a participação do docente na supervisão.

Vejo que há momentos que se faz necessário um intermédio do docente, como conversamos muito em grupo. Iniciativa e confiança são termos diferentes, que muitas vezes são confundidos pelos profissionais que tentam enquadrar-se neste novo contexto da enfermagem e da docência, não é fácil!. (...). Ao se estipular um acordo entre as partes envolvidas (aluno, docente e enfermeiro supervisor) sobre o objetivo do estágio e a sua avaliação para que todos "falem a mesma língua", e reaver este acordo e suas pontuações no meio do estágio facilitará a compreensão da visão do "outro" e auxiliará nos pontos a serem melhorados (E6 Reflexão descritiva).

Houve reconhecimento do valor do estágio para a formação profissional como contribuição para a apropriação do trabalho do enfermeiro.

O estágio supervisionado é uma excelente oportunidade para nós alunos vivenciarmos o papel de enfermeiro ainda como alunos, e não como enfermeiros já formados, nos dando chance de norteamos melhor nossas ações ao final de nossa formação, diminuindo as chances de termos um "choque" ao nos depararmos com os 
problemas diários enfrentados pelo enfermeiro. Deixo como sugestão, a disciplina de gestão comunicar-se melhor com esta disciplina, a fim de organizar e distribuir melhor a carga horária (E9 Reflexão descritiva).

Em outro trecho:

Hoje consigo ter uma visão mais abrangente de como é o funcionamento de um serviço hospitalar, sua rotina e do trabalho e papel do enfermeiro dentro de uma unidade. Até o quarto ano da faculdade, nós alunos, vamos para o campo de estágio, mas não criamos vínculo com a equipe de enfermagem e praticamente não vemos e percebemos a atuação do enfermeiro, acredito que por algumas razões: primeiro, porque o estágio tem uma duração muito curta, o que impossibilita a criação desse vínculo; segundo porque estamos acompanhados de um docente, e por essa razão, não aprendemos "a nos virarmos sozinhos"; e terceiro, que a nossa visão como aluno do serviço é muito limitada, pois ficamos apenas com os cuidados diretos do paciente, e não nos atentamos a outras questões que envolvem todo aquele serviço, como a parte administrativa, resolução de problemas e tomada de decisões (E3 Reflexão dialógica).

Outro aspecto presente nas reflexões é a condição do estagiário que se percebe ora como mão de obra para o serviço, ora como aprendiz:

Foi inevitável também ser vista como mão de obra em muitos momentos e ser contada na escala como uma profissional já formada, o que às vezes me preocupava e me fazia pensar: "espera aí, será que posso mesmo? Ainda sou aluna! Responsabilidades e confianças que muitas vezes fizeram muito bem ao ego e à autoestima, mas que me preocupou também. Há limites até onde o aluno pode ir, não há? Mesmo que ele seja capaz e tenha confiança pra isso, é necessário supervisão, pois contamos primeiramente com o bem-estar de seres humanos, e às vezes é necessário experiência para algumas atitudes e responsabilidades (E6 Reflexão dialógica).

\section{DISCUSSÃo}

Os estudantes de enfermagem vêm realizando reflexões que se enquadram nas modalidades de narração descritiva, reflexão descritiva, reflexão dialógica e reflexão crítica. Um estudo sobre a terapia ocupacional $^{(11)}$ apresenta resultado semelhante, mas com ausência de reflexão crítica. Ainda que presente em apenas um dos materiais analisados, acredita-se que a reflexão crítica pode ser estimulada com o uso do portfólio, ferramenta que durante a graduação pode oferecer o desenvolvimento de um olhar para o cotidiano que ultrapasse a descrição e a constatação, favorecendo uma apreensão da complexidade do mundo do trabalho e do trabalho do enfermeiro ${ }^{(15)}$, através do compartilhamento de experiências ${ }^{(5)}$. O pensamento crítico envolve questionar as vivências e os saberes que o sustentam e, então, apontar possibilidades para modificar o que está dado. Alguns autores sugerem que haja um mentor, facilitador, que auxilie nesse processo, assim, diante das vivências e impressões sistematizadas no portfólio, o mentor ao ler tais colocações colaboraria com o processo de instigar o aluno a fazer perguntas e propor soluções ${ }^{(17)}$.

Destaca-se que não se trata de hierarquizar as formas de reflexão e nem mesmo de desvalorizar qualquer um dos tipos de narrativas apresentadas, salienta-se que é preciso conhecer o processo pelo qual passam os estudantes para construir suas reflexões. É necessário que o estudante seja acolhido em suas limitações e tenha garantido o desenvolvimento de sua maturidade profissional ${ }^{(9)}$, o que pode auxiliar os docentes, os enfermeiros supervisores e os próprios estudantes que ainda se mostram resistentes e receosos a essa abordagem pedagógica, em decorrência da inexistência de discussões e, assim, haver o avanço na prática crítico-reflexiva ${ }^{(18)}$.

Outra questão importante é que a resistência de alunos e também de docentes ao uso dessa ferramenta pode estar ligada à falta de conhecimento de como utilizá-la, assim, quando utilizado como instrumento avaliativo, os critérios de julgamento e o que se espera com o seu uso devem ser muito bem esclarecidos, o que poderá diminuir a ansiedade dos alunos e fazer com que o portfólio cumpra seu objetivo de instrumento formativo ${ }^{(17)}$.

O predomínio da narração descritiva indica um momento necessário da aproximação do estudante com o cenário de aprendizagem e com a prática profissional, os quais são descritos como diferentes dos demais vivenciados na graduação, sendo, portanto, necessária a descrição, expressa por meio de impressões subjetivas e com tentativas superficiais para explicá-las.

Com relação à reflexão descritiva, observou-se nos exemplos a presença tanto da busca de justificativas na literatura científica como na própria experiência. Este recurso é citado(19) como forma de habilitar o aluno a 
seguir ou reconstituir trajetórias metodológicas percorridas por cientistas, a partir do senso de busca e da disciplina de trabalho envolvidos no processo de pesquisa, ressignificando este processo que passa a ser compreendido não mais como cristalizador de conhecimentos armazenados, mas, como reconstrutor da ciência ${ }^{(19)}$.

A capacidade de movimentar-se, ante uma crescente fonte de informações com intensa velocidade de mudanças do conhecimento produzido, é uma característica desejável ao profissional críticoreflexivo ${ }^{(20)}$.

O portfólio como ferramenta de aprendizagem no contexto do ECS proporciona a aplicação e a recriação de conhecimentos e do exercício da associação de sabedoria, criatividade e reflexão crítica, uma vez que envolve o fazer pesquisa e assim como nesta é conduzido por situações-problema de complexidades e de contextos variados ${ }^{(19)}$.

Apesar de os estudantes do último ano apresentarem portfólios com narrativas predominantemente descritivas, a perspectiva críticoreflexiva vem sendo trabalhada durante a formação na instituição de ensino pesquisada(21), o que pode ser evidenciado no fato de que foi possível perceber que a descrição era feita, tendo como parâmetro o que se aprendeu, como no fragmento:

(...) os impressos não são utilizados de forma adequada. A admissão do paciente é sempre realizada, utilizando-se o impresso que auxilia na coleta de dados, porém dificilmente realiza-se o exame físico que deveria sempre ser preenchido junto com o da admissão (E6).

Tal evidência pode indicar que a associação que se espera entre os conteúdos trabalhados e a vivência(22) esteja ocorrendo, embora ainda haja limitações para transpor isso de forma sistematizada na elaboração dos portfólios. Tal perspectiva consiste em elemento fundamental para a construção da aprendizagem atitudinal $^{(9,23)}$

Autores $^{(2)}$ afirmam que geralmente os estudantes não trabalham com a integração dos conteúdos das diferentes disciplinas, já que não conseguem vislumbrar o quê (como) poderia unir ou integrar tais conteúdos. O portfólio é visto nesse sentido como uma possibilidade de integração entre disciplinas, entre vivências e experiências, por permitir que o aluno dialogue consigo mesmo, ao refletir, e com o docente e supervisor do estágio mediante a leitura do portfólio e discussão do mesmo. Dito de outro modo, por meio do portfólio é possível que haja uma integração, inclusive, dos agentes envolvidos no processo de formação do aluno, estudante, professor da disciplina e supervisor de campo $^{(22)}$.

Os fragmentos de reflexões dialógicas apresentam o diálogo do estudante consigo, documentando os movimentos de criação de novos sentidos às vivências e aos significados, diante das contradições constatadas no ECS. Nessa modalidade de reflexão, há expressão de autoavaliação e de implicação do próprio estudante para a construção de novas realidades.

Assim, o estudante considera-se "imerso" na realidade vivenciada e não alguém que olha de fora algo e propõe soluções, torna-se sujeito participante do processo ensino-aprendizagem ${ }^{(9,16)}$. Esse aspecto nos parece ser potencializador para a produção de ações integrais em saúde que proponham o cuidado do sujeito em sua totalidade.

No entanto, alguns autores pontuam que, por ser no processo reflexivo desencadeado na elaboração do portfólio que o aluno tem a possibilidade de identificar lacunas, habilidades e competências que ainda precisam ser adquiridas, isso pode gerar certa relutância na elaboração do material, uma vez que o estudante diante dessa reflexão se expõe a medos e fraquezas, e é nesse ponto que são necessários professores e supervisores como facilitadores desse processo ${ }^{(24)}$.

Considera-se que em uma narrativa os assuntos expressos, a forma de apresentá-los, as expressões, os lapsos e as contradições possuem muitos significados que podem ser explorados com a finalidade pedagógica ${ }^{(25)}$.

Assim, pode-se dizer que nas categorias apresentadas há expressões de algumas das principais preocupações dos estudantes que no caso se relaciona ao campo de estágio, ao trabalho do enfermeiro e ao seu aprendizado, durante o estágio.

$\mathrm{Na}$ primeira categoria, o campo de estágio é o principal objeto de inquietação e de reflexões nos portfólios. Ele se apresenta no movimento de integração e separação entre as teorias estudadas e aprendidas sobre a prática e a práxis, denotando que as práticas de ensino mantêm ênfase na demonstração de técnicas e procedimentos $^{(18)}$. Isso pode ser um indício de que a formação de enfermeiros está orientada pela concepção mais cartesiana de modelos e teorias sobre a realidade para aplicação na prática, mescladas com concepção mais compreensiva do mundo, que parte da noção de uma realidade múltipla e cambiante que precisa ser refletida à luz de vários referenciais ${ }^{(9)}$. 
O raciocínio e a problematização sobre a inadequação de determinados aspectos dos serviços de saúde levam os estudantes a convocar as instâncias de formação para uma participação mais efetiva nos serviços com o compromisso de sua transformação.

Do contrário, (re)instala-se a ideia de modelos pensados a priori e no interior da academia que devem ser transferidos para os serviços de saúde, o que nas mudanças propostas para formação pretende-se superar. Sobre essa questão alguns autores ${ }^{(1)}$ ponderam que, no processo de aproximação entre academia e serviços de saúde e na construção de compromissos entre ambas, a responsabilidade pública e a relevância social da universidade serão ampliadas na medida em que trazem para o contexto da educação o conjunto das diretrizes do SUS, em especial a integralidade ${ }^{(1)}$.

Destaca-se, ainda, que os temas do acolhimento aos usuários, desgastes dos trabalhadores de saúde, dificuldades da implementação da atenção básica estiveram no foco das reflexões dos estudantes. Esses temas são considerados problemáticos pelas instâncias organizacionais da saúde no país, demonstrando a capacidade de os estudantes apreenderem problemas críticos do sistema de saúde brasileiro que têm motivado a implementação de políticas públicas, como é o caso da Política Nacional de Humanização ${ }^{(9)}$ que trata da ambiência, do trabalho em equipe e do acolhimento, entre outros.

Considera-se importante a explicitação das dificuldades dos estudantes e trabalhadores envolvidos, usuários de serviços de saúde e equipe pedagógica em outros espaços além do portfólio, a fim de que haja organização e luta por melhores condições de trabalho e de atenção à saúde. De outro modo, corre-se o risco de que o portfólio sirva para a deposição da indignação frente às condições dos serviços de saúde, transformando-o em instrumento de acomodação frente à dilemas e conflitos.

$\mathrm{Na}$ categoria apropriação e análise do trabalho do enfermeiro, evidencia-se como objeto das reflexões a forma como o enfermeiro do serviço atua e como deveria atuar. Aqui destaca-se uma contradição, pois a capacidade reflexiva identificada em várias modalidades não dá conta de desnudar as ideologias predominantes. Uma delas é a da aplicação da sistematização da assistência de enfermagem a partir da vontade individual dos enfermeiros. Para os estudantes, a questão da ausência da sistematização da assistência de enfermagem ocorre por questões relativas aos próprios enfermeiros, como exemplifica o fragmento:
Temos um impresso para admissão e alta do paciente e uma de exame físico, porém, os impressos não são utilizados de forma adequada (E6 Narração descritiva).

Não se consideram o número de trabalhadores efetivos, as condições de trabalho, a história da profissão e os motivos pelos quais a sistematização da assistência vem sendo preconizada.

Também aparece como problemática a falta de liderança.

Volto a ressaltar, acho que isso pode ser atribuído à falta de liderança e comprometimento (E10 Reflexão crítica).

A responsabilidade da articulação da equipe recai individualmente sobre o trabalhador, não se consideram as disputas históricas e corporativas presentes nas equipes de saúde, a diferença de valor social de cada trabalho e a hierarquia, entre outros aspectos.

Na terceira categoria apresentada, evidencia-se uma perspectiva positiva do ECS para a formação do enfermeiro, assinalando $o$ crescimento $e$ amadurecimento durante o ECS. Esse aspecto reafirma resultados de outras pesquisas ${ }^{(4)}$. Ressalta-se que o ECS pode ser considerado como um momento de síntese do curso de enfermagem ${ }^{(4)}$, e como tal pode ser um analisador das contradições e dilemas experienciados, durante a graduação.

Um dos dilemas é referente ao papel do estudante que se vê em certo "entre": não é profissional ainda, é um aluno diferente, é concluinte de um curso e é um "quase" enfermeiro, como descrito no trecho:

Foi inevitável também ser vista como mão de obra em muitos momentos e ser contada na escala como uma profissional já formada, o que às vezes me preocupava e me fazia pensar: "espera aí, será que posso mesmo? Ainda sou aluna! (E6 Narração descritiva).

Assim, um dilema a ser trabalhado é o uso do estudante como "mão de obra" nos serviços de saúde que podem operar com a lógica de uma troca implícita: o aceite de estagiários com a expectativa de colaboração em termos de mão de obra.

Outro aspecto a ser problematizado é sobre o aprendizado do trabalho dos enfermeiros, durante toda a graduação, que aparece como distante e parcial. A narrativa de E3 exemplifica esse aspecto. 
Até o quarto ano da faculdade, nós alunos, vamos para o campo de estágio, mas não criamos vínculo com a equipe de enfermagem.

Aparentemente ainda há o predomínio de estágios de curta duração nos quais a formação de vínculos e de compromisso dos estudantes e professores para com os serviços de saúde e dos trabalhadores para com a formação fica inviabilizada, devido ao curto período de duração.

A presença do docente no campo de estágio foi solicitada pelos estudantes, o que pode ser um indício da fragilidade da articulação ensino-serviço, ou resultado do desconforto abrupto ante um processo de acompanhamento direto e tutelador, para um acompanhamento a distância que tem por intenção a produção da autonomia.

Sobre o papel do docente, autores ${ }^{(19)}$ afirmam que este tem grande importância no processo ensinoaprendizagem, tanto como mediador entre as vivências atuais quanto reforçando em conjunto com o aluno as suas experiências anteriores. Os mesmos autores concluíram que, nas estratégias de ensino onde há promoção de reflexão, é o próprio aluno que indaga durante todo o processo, e desse modo há exigência de que o professor também reflita sobre o ensinaraprender $^{(19)}$, uma vez que este ensinar-aprender conteúdos de forma articulada com livros, banco de dados e contextos sociais permite o diálogo entre pares, docentes e alunos e auxilia no desenvolvimento de métodos pedagógicos que transcendem à reprodução de conhecimento, o que é coerente tanto na vivência de um ECS quanto no registro deste no portfólio reflexivo.

Diante da apresentação de todas as categorias que emergiram do estudo e do seu conteúdo, percebe-se que os alunos apresentam suas impressões e mesmo os sentimentos e críticas foram contemplados nos relatos analisados, esse achado diverge do que foi mencionado em um estudo, no qual pontua-se que, quando há o uso do portfólio com fins avaliativos, os alunos omitem pensamentos e sentimentos íntimos, uma vez que fazem a leitura dessa exposição em um documento como o portfólio como uma "invasão de privacidade", sendo por isso incentivados a construirem seus portfólios tendo em vista o que o professor gostaria de ler, perdendo autenticidade do relato e diminuindo assim seu valor formativo no processo de aprendizagm ${ }^{(24)}$.

\section{CONCLUSÃO}

Os estudantes apresentaram em seus portfólios, narrativas do tipo: narração descritiva, reflexão descritiva, reflexão dialógica e reflexão crítica. Houve predominância da modalidade de narração descritiva, o que indica que ao fazê-lo está também se apropriando do processo de trabalho do serviço de saúde e elaborando sua vivência como estudante e futuro enfermeiro. Mesmo com a predominância de textos descritivos, a presença de constatações que se opõem ao que é recomendado na teoria faz acreditar que o propósito do portfólio, de favorecer a aproximação entre teoria e prática, tem sido em parte alcançado, embora, ainda existam dificuldades em sistematizar isso na construção do portfólio.

A análise dessas reflexões apontou que o foco das mesmas no ECS é o serviço de saúde em sua organização e dificuldades, o trabalho do enfermeiro e o aprendizado na disciplina, com isso entende-se que assuntos de grande relevância tem sido apreendidos pelo alunos do ECS e sistematizados no portfólio. Destacou-se - limite das reflexões com relação aos aspectos ideológicos que consideram as dificuldades como obstáculos para além dos indivíduos, o que pode se justificar pela pequena ocorrência da reflexão crítica.

Os estudantes ainda apontaram em suas reflexões as potencialidades e limites do ECS, indicando necessidade de reflexão dos formadores, dos enfermeiros supervisores e estudantes sobre a relação ensino-serviço e sobre o cuidado realizado.

Dessa forma, as reflexões analisadas indicam que o portfólio pode ser uma ferramenta para auxiliar o estudante no desenvolvimento de seu processo críticoreflexivo e também um instrumento para a análise da formação em si. No entanto, também demonstra que há lacunas no processo ensino-aprendizagem da habilidade de reflexão crítica, podendo estas estarem relacionadas a aspectos mais estruturais da organização curricular; habilitação docente para a formação de profissionais reflexivos e ausência de investimentos junto aos enfermeiros de serviço quanto a essa perspectiva de formação (crítico-reflexiva).

A construção do portfólio enquanto uma ferramenta de aprendizagem, e não apenas de avaliação, deve ser um processo acompanhado pelo docente e pelo supervisor de campo, uma vez que os facilitadores (docente e enfermeiro supervisor), tomando ciência do processo desencadeado, poderiam instigar o aluno a questionar e assim refletir sobre suas vivências, favorecendo assim o desenvolvimento de narrativas do 
tipo reflexão descritiva, reflexão dialógica e reflexão crítica. Outra questão que também seria desenvolvida pelo acompanhamento contínuo do processo de construção do portfólio é a resolução de problemas enfrentados pelo aluno no ECS, bem como a construção

\section{REFERÊNCIAS}

1. Ceccim RB, Feuerwerker LCM. Mudança na graduação das profissões de saúde sob o eixo da integralidade. Cad Saude Publica [Internet]. 2004 [acesso em: 30 set 2014];20(5):140010. Disponível em: http://dx.doi.org/10.1590/S0102$311 \times 2004000500036$.

2. Albuquerque VS, Batista RS, Tanji S, Moço ETSM. Currículos disciplinares na área de saúde: ensaio sobre saber e poder. Interface (Botucatu) [Internet]. 2009 [acesso em: 30 set 2014];13(31):261-72. Disponível em:

http://dx.doi.org/10.1590/S1414-32832009000400003. 3. Resolução CNE/CES no 3, de 7 de novembro de 2001 (BR) [Internet]. Institui Diretrizes Curriculares Nacionais do Curso de Graduação em Enfermagem. Diário Oficial da União. 09 nov 2001 [acesso em: 30 set 2014]. Disponível em: http://portal.mec.gov.br/cne/arquivos/pdf/CES03.pdf. 4. Colliselli L, Tombini LHT, Leba ME, Reibnitz KS. Estágio curricular supervisionado: diversificando cenários e fortalecendo a interação ensino-serviço. Rev Bras Enferm [Internet]. 2009 [acesso em: 30 set 2014];62(6):932-7. Disponível em: http://dx.doi.org/10.1590/S0034-71672009000600023. 5. Friedrich DBC, Gonçalves AMC, Sá TS, Sanglard LR, Duque DR, Oliveira GMA. The Portfolio as an Evaluation Tool: an Analysis of its Use in an Undergraduate Nursing Program. Rev Lat Am Enfermagem [Internet]. 2010 [acesso em: 30 set 2014]; 18(6):1123-30. Disponível em: http://dx.doi.org/10.1590/S0104-11692010000600012. 6. Sá-Chaves I. Portfólios: No fluir das concepções, das metodologias e dos instrumentos. In: Sá-Chaves I. Portfólios Reflexivos: estratégias de formação e de supervisão. Aveiro: Universidade; 2000. p.11-17.

7. Cotta RMM, Mendonça ET, Costa GD. Portfólios reflexivos: construindo competências para o trabalho no Sistema Único de Saúde. Rev Panam Salud Publica [Internet]. 2011 [acesso em: 30 set 2014$] ; 30(5): 415-21$. Disponível em: http://dx.doi.org/10.1590/S1020-49892011001100003. 8. Williams GA, Park JR, Traynor V, Nairn S, O'Brien E, Chapple M et al. Lecturers' and students' perceptions of portfolios in an English School of Nursing. J Clin Nurs [Internet]. 2009 [acesso em: 30 set 2014];18(8):1113-22. Disponível em: http://dx.doi.org/10.1111/j.1365-2702.2008.02553.x. 9. Casate JC, Corrêa AK. The humanization of care in the education of health professionals in undergraduate courses. Rev Esc Enferm USP [Internet]. 2012 [acesso em: 30 set 2014]; 46(1):219-26. Disponível em: http://dx.doi.org/10.1590/S008062342012000100029 .

10. Minayo MC. O desafio do conhecimento: pesquisa qualitativa em saúde. 6.ed. São Paulo: Hucitec/ABRASCO; 1999. 11. Marcolino TQ, Mizukami MGN. Narrativas, processos reflexivos e prática profissional: apontamentos para pesquisa e formação. Interface (Botucatu) [Internet]. 2008 [acesso em: 30 set 2014];12(26):541-7. Disponível em: http://dx.doi.org/10.1590/S1414-32832008000300007. 12. Bardin L. Análise de conteúdo. $5^{a}$ ed. São Paulo: Edições 70; 2011.

13. Sordi MRL, Silva MM. O uso de portfólios na pedagogia universitária: uma experiência em cursos de enfermagem. Interface (Botucatu) [Internet]. 2010 [acesso em: 30 set 2014];14(35):943-53. Disponível em:

http://dx.doi.org/10.1590/S1414-32832010005000018. 14. Mizukami MGN. A escola e a aprendizagem da docência: processos investigação e formação. São Carlos: EdUFSCar; 2002. 15. Matumoto S, Fortuna CM, Kawata LS, Mishima SM, Pereira de propostas conjuntas para a resolução de problemas.

As lacunas acima apontadas se constituem em elementos que podem ser explorados em estudos futuros para a qualificação da formação do enfermeiro.

MJ. Nurses' clinical practice in primary care: a process under construction. Rev Lat Am Enfermagem [Internet]. 2011 [acesso em: 30 set 2014];19(1):123-30. Disponível em:

http://dx.doi.org/10.1590/S0104-11692011000100017. 16. Cotta RMM, Costa GD, Mendonça ET. Portfólio reflexivo: uma proposta de ensino e aprendizagem orientada por competências. Cien Saude Colet [Internet]. 2013 [acesso em: 30 set 2014];18(6):1847-56. Disponível em: http://dx.doi.org/10.1590/S1413-81232013000600035. 17. Corcoran J, Nicholson C. Learning portfolios--evidence of learning: an examination of students' perspectives. Nurs Crit Care [Internet]. 2004 [acesso em: 30 set 2014];9(5):230-7. Disponível em: http://dx.doi.org/10.1111/j.13621017.2004.00078.x. 18. Lazzarini DD, Pedro ENR, Sanches MO, Jung W. Estratégias de ensino do cuidado em enfermagem: um olhar sobre as tendências pedagógicas. Rev Gaucha Enferm [Internet]. 2011 [acesso em: 30 set 2014];32(4):688-94. Disponível em http://www.scielo.br/scielo.php?script=sci_arttext\&pid $=$ S198314472011000400008 .

19. Patrício ZM, Silvério MR, Ribeiro IM, Felisbino JE, Brodbeck IM, Martins GWM et al. Sistematização de estratégias de ensinaraprender pesquisa na graduação. Interface (Botucatu) [Internet]. 2011 [acesso em: 30 set 2014];15(39):1159-72. Disponível em: http://dx.doi.org/10.1590/S1414-32832011005000029. 20. Chirelli MQ, Mishima SM. A formação do enfermeiro críticoreflexivo no curso de enfermagem da Faculdade de Medicina de Marília - FAMEMA. Rev Lat Am Enfermagem [Internet]. 2003 [acesso em: 30 set 2014];11(5):574-84. Disponível em: http://dx.doi.org/10.1590/S0104-11692003000500003. 21. Paranhos VD, Mendes MMR. Currículo por competência e metodologia ativa: percepção de estudantes de enfermagem. Rev Lat Am Enfermagem [Internet]. 2010 [acesso em: 30 set 2014];18(1):109-15.Disponível em:

http://dx.doi.org/10.1590/S0104-11692010000100017.

22. Harris S, Dolan G, Fairbairn G. Reflecting on the use of student portfolios. Nurse Educ Today [Internet]. 2001 [acesso em: 30 set 2014$] ; 21(4): 278-86$. Disponível em:

http://dx.doi.org/10.1054/nedt.2000.0545.

23. Prado RA, Prado ML, Reibnitz KS. Desvelando o significado da avaliação no ensino por competência para enfermeiros educadores. Rev. Eletr. Enf. [Internet]. 2012 [acesso em: 30 set 2014];14(1):112-22. Disponível em: http://dx.doi.org/10.5216/ree.v14i1.12705.

24. McMullan M, Endacott R, Gray MA, Jasper M, Miller CM, Scholes $\mathrm{J}$ et al. Portfolios and assessment of competence: a review of the literature. J Adv Nurs. [Internet]. 2003 [acesso em: 30 set 2014];41(3):283-94. Disponível em:

http://dx.doi.org/10.1046/j.1365-2648.2003.02528.x. 25. Cunha MI. Conta-me agora! As narrativas como alternativas pedagógicas na pesquisa e no ensino. Rev. Fac. Educ. [Internet].1997 [acesso em: 30 set 2014]; 23(1/2). Disponível em: http://dx.doi.org/10.1590/S0102-25551997000100010.

Artigo recebido em 01/08/2013

Aprovado para publicação em 22/04/2014

Artigo publicado em 30/09/2014. 